\title{
Os sentimentos das mulheres climatéricas em relação à imagem corporal $^{*}$
}

Fabiani Breancini**

Eleonor Moretti***

\section{RESUMO}

O climatério é um processo universal que atinge toda mulher de meiaidade, caracterizando-se como um período de alterações dos fatores biológicos, psicológicos e sociais. Assim, objetivou-se conhecer os sentimentos da mulher climatérica sobre a sua imagem corporal, realizando um estudo exploratório-descritivo, de abordagem qualitativa, com sete mulheres climatéricas da cidade de Carazinho-RS. Os dados foram coletados utilizando-se a técnica de discussão grupal e entrevistas com aplicação de um instrumento-guia, sendo submetidos a análise de conteúdo na modalidade temática e posterior interpretação com base no referencial teórico e nos objetivos propostos. Evidenciaram-se as seguintes classes: sentimentos expressos pelas mulheres climatéricas referentes à fase da vida em que se

Trabalho desenvolvido na disciplina de Iniciação Científica em Enfermagem do Curso de Enfermagem da Universidade de Passo Fundo-RS.

** Acadêmica do IX nível do Curso de Enfermagem da Universidade de Passo Fundo.

*** Mestre em Enfermagem. Professora Titular III das disciplinas de Enfermagem na Saúde da Mulher I e II do Curso de Enfermagem da Universidade de Passo Fundo. e-mail: fabibreancini@ig.com.br ; enfermagem@saúde.upf.tche.br Recebido em 10.04.02 Aprovado em 24.04.02 
encontram, preconceitos sociais em relação à mulher climatérica e, surpreendentemente, preocupação com o futuro da juventude atual. Com o estudo, foi possível compreender mais uma fase de transformações da vida da mulher, reconhecendo a necessidade de reconstruir a imagem da climatérica, tanto pessoal como socialmente, visando a sua qualidade de vida.

UNITERMOS: climatério, imagem corporal, sentimentos.

\section{INTRODUÇÃO}

O climatério é um processo físiológico de mudanças físicas e emocionais, constituído pelo cessamento das menstruações, um evento universal que faz parte da evolução de todas as mulheres que atingem a meia-idade, aproximadamente dos 35 aos 75 anos. Nessa evolução intervêm fatores biológicos, psicológicos e sociais, despertando na mulher conflitos e incertezas quanto a sua sexualidade, dúvidas sobre o que está ocorrendo com seu corpo, afastamento do meio social, medo da velhice, sensação de proximidade com a morte e uma distorção da sua imagem corporal. Por isso, o climatério é uma fase da vida da mulher que exige dela adaptação a uma nova situação.

Segundo dados do censo mundial de 1995, a população feminina era de 2,8 bilhões, dos quais 1,4 bilhões eram de mulheres no climatério. Conforme estudos do IBGE, no ano de $2025,72 \%$ dos idosos estarão nos países em desenvolvimento, sendo o Brasil o sexto país em população idosa, pois a expectativa de vida vem aumentando significativamente. Assim, a mulher viverá no climatério cerca de 25 a 35 anos, ou seja, um terço da sua vida.

Para a mulher, esse período é ainda mais difícil, pois, a partir da meiaidade, iniciam-se as primeiras manifestações do climatério, denominação esta vinda do grego klimater (Marinho, 1995), que significa "ponto crítico da vida".

Martins (1996) entende que o climatério, por ocasionar sinais e sintomas aproximadamente dos 40 aos 65 anos, "é considerado uma síndrome que tem a menopausa (parada definitiva das menstruações resultante do término da atividade folicular ovariana) como um marco" (p. 30). O climatério possui três fases descritas, segundo o autor: pré-menopausa, menopausa e pós-menopausa. "A pré-menopausa se inicia no final da menacme (período reprodutivo da mulher) e se estende até a menopausa, durando em média 4 anos. Após a menopausa, o climatério se prolonga até a senectude (período não reprodutivo da mulher) e perdura até os 70 anos" (p. 30).

Segundo Marinho (1995), a maioria dos sinais e sintomas típicos do climatério resulta da diminuição dos níveis de estrogênios circulantes. Essas alterações endócrinas tem um forte impacto sobre as funções psíquicas e vegetativas do organismo feminino, podendo resultar em várias manifestações, que Martins (1996) esquematiza em quatro grupos distintos:

a) alterações psíquicas: para a mulher, neste período reduzem-se as possibilidades de auto-realização, o futuro parece vazio e não instila entu- 
siasmo; é hora de reduzir a vaidade, perdeu-se a juventude, o viço, a beleza física e a corte dos homens; cumpriu-se a tarefa de ser esposa e mãe; a mulher considera-se, então, uma desativada de suas principais funções sociais e rodeada de solidão com o que poderá ocorrer labilidade de humor, nervosismo, intolerância e irritabilidade, diminuição da libido, depressão;

b) alterações provenientes de distúrbio nervosos e dos vasos sangüíneos: fogachos (ondas de calor), sudorese, taquicardia, formigamentos, vertigens, cefaléias, esquecimento, astenia, doenças cardiovasculares;

c) alterações do aparelho geniturinário: dispareunia, secura da mucosa vaginal, prurido, cistites, polaciúria, disúria, incontinência urinária aos pequenos e médios esforços;

d) alterações da musculatura, pele e esqueleto ósseo: pele seca e delgada, atrofia da musculatura em geral, dores ósseas, queixas articulares, osteopenia e osteoporose. Todos os sintomas enumerados aparecem em curto prazo, com exceção das moléstias cardiovasculares, osteopenia e osteoporose, que se apresentam a longo prazo. Todas as mulheres apresentam sintomatologia no climatério e menopausa, entretanto uma a cada quatro terá sintomas exacerbados. Mas, de acordo com Halbe (1995, p. 42),

(...) fatores sócio-culturais também modificam a experiência psicológica do climatério e meia-idade. Grupo sócio econômico mais baixo, nível educacional inferior, afastamento dos filhos do lar e suporte familiar inadequado tem sido relacionados com maior prevalência de sintomas climatéricos e a influência desses fatores na síndrome do climatério depende também da personalidade e do contexto social em que a mulher está inserida, dessa forma, mulheres de cultura ocidental onde se valoriza a juventude e a aparência física, enquanto o envelhecimento é visto de forma negativa, tendem a apresentar mais queixas clínicas durante $o$ climatério. Então, a interação entre fatores hormonais, psicológicos e sócio-culturais é que determina a presença ou ausência, $e$ a intensidade da sintomatologia apresentada, sendo, portanto, variável de indivíduo para indivíduo, e entre diferentes culturas.

Para aliviar as manifestações da síndrome do climatério, surgiu a terapia de reposição estrogênica, que começou a expandir-se na década de 70 , sendo até os dias de hoje a arma disponível para tratar alterações endócrinas. A terapia deve ser individualizada para cada caso, tentando identificar em cada paciente o risco para diversas patologias, como cardiopatias, osteoporose, câncer de mama e endométrio. Porém, tão importante ou mais que a hormonioterapia são as mudanças de hábitos de vida, como abandonar a tabagismo, praticar exercícios, corrigir a alimentação e diminuir o estresse diário, além do suporte psicológico, enfim, há necessidade de qualidade de vida (Marinho, 1995, p. 5). 
As mudanças hormonais do climatério trazem mudanças adicionais que penetram na consciência da mulher. Pode-se, então, avaliar o quão significativo é para a mulher a vivência desta fase da vida, pois o culto ao belo, ao jovem, a extrema valorização que a sociedade atribui a tudo que é novo, perfeito, justificam os sentimentos confusos e a dificuldade de adaptação que a mulher enfrentará nesse meio, de certa forma hostil, às suas manifestações, tanta físicas quanto comportamentais. Contudo, não há como negar que todas as mulheres vão sofrer alterações em maior ou menor intensidade e terão de se adaptar a um novo estilo de vida de acordo com as limitações que lhe ocorrerem (Haas, 1995); com isso, o aspecto psicológico será afetado. É o que Freedman (1994, p. 203) descreve:

(...) surgirão ansiedades, melancolias e depressão, pois o modo como você se sente sobre sua imagem corporal envelhecendo certamente influencia seu comportamento e sua auto-estima. Sua ansiedade pode destruir relacionamentos, inibir sua expressão sexual e limitar os objetivos que ela determina para si mesma.

Imagem corporal é a representação que um indivíduo faz do seu corpo em sua mente ou em seu espírito. Considerando tratar-se de uma representação psicológica, a imagem corporal integra os níveis físico, emocional e mental em cada ser humano, com respeito aos sentimentos da sua corporalidade. No conceito referido por Taggart (apud Moretti, 1992, p. 14):

(...) a imagem corporal é a imagem mental que temos de nós mesmos, é mais do que uma fotografia psíquica, piano, é um perfil conceitual tridimencional e complexo de fatores e percepções do nosso corpo. Esses fatores e percepções são baseados em nossa aparência exterior, em nossas sensações internas do corpo, em reações de outras pessoas relativas ao nosso corpo, derivadas de identidades com outros.

Então, como vive a mulher climatérica neste período, com sua autoestima, auto-imagem e autoconceito influenciados pelo estereótipo cultural? Em resposta à questão, Freedman (1994, p. 270-272) diz que

(...) irão surgir então conseqüências da aversão ao corpo, que são angústia física e emocional. A aversão ao corpo nos mantém constrangidas. Captadas no reflexo do espelho acabamos nos esquecendo de cuidar da pessoa que está dentro da imagem. Se a aversão ao corpo é uma doença contagiosa, o antídoto para ela é o amor ao corpo, um elixir de emoções, atitudes e ações positivas. Amar seu corpo significa desfrutar dele, usá-lo, tocá-lo e vê-lo com prazer. Não é a beleza, mas a auto-estima que constrói o amor ao corpo. Alguém com uma auto-estima elevada tende a ver 
seu corpo favoravelmente, independentemente de qual seja na verdade sua aparência. Para conseguir o amor ao corpo você precisa ir além da sua aparência e se concentrar também em seus outros valores pessoais.

A mulher precisará, então, rever seus sentimentos, pois, como esclarece Viscott (1982), os sentimentos são a maneira como percebemos que estamos vivos. O que sentimos a respeito de qualquer coisa reflete nossa história e desenvolvimento, nossas influências passadas, nossa agitação presente e nosso potencial futuro. Os sentimentos podem ser disfarçados, negados, racionalizados, mas quando um sentimento é evitado, freqüentemente seus efeitos dolorosos são prolongados e torna-se cada vez mais difícil lidar com eles.

Por essa razão é que o relacionamento enfermeira/paciente deve ser de confiança, de modo que a pessoa passa falar, trabalhar os seus sentimentos e resolver os problemas de maneira apropriada a situação, pois o reconhecimento da realidade inicia quando a pessoa começa a redefinir para si mesma a idéia de que uma mudança na função ou estrutura do corpo traz implicações para seu estilo de vida (Murray apud Moretti, 1992, p. 42).

Assim, este estudo objetivou conhecer os sentimentos da mulher climatérica sobre a imagem corporal, visando a melhoria de sua qualidade de vida.

\section{METODOLOGIA}

Trata-se de um estudo exploratório, descritivo, de abordagem qualitativa, realizado com sete mulheres climatéricas da cidade de Carazinho-RS, escolhidas de forma intencional dentre aquelas que compõem o círculo de conhecimento da pesquisadora. São mulheres que aceitaram participar de livre e espontânea vontade após receberem os esclarecimentos sobre o desenvolvimento do estudo, confirmando sua adesão através do termo de consentimento livre e esclarecido, que continha as garantias previstas na resolução 196/96 do Conselho Nacional de Saúde.

Os dados foram coletadas no mês de agosto de 2001, utilizando-se a técnica de discussão grupal. Em virtude da dificuldade de gravação da sessão grupal, por causa da sobreposição das falas, optou-se por realizar entrevistas semi-estruturadas individuais conduzidas por um instrumento-guia. Os dados obtidos foram analisados qualitativamente, considerando-se a conteúdo das falas das respondentes, tanto na discussão grupal, quanto nas entrevistas individuais. Após a leitura e releitura dos depoimentos, constituiu-se $o$ corpus do qual se extraíram as unidades de significação para a construção das categorias e posterior interpretação com base no referencial teórico e nos objetivos propostos. 


\section{APRESENTAÇÃO DOS RESULTADOS}

A partir da análise do corpus de falas das respondentes, obtido tanto da discussão grupal quanto das entrevistas individuais, extraíram-se três classes, que se referem aos sentimentos da mulher climatérica, aos preconceitos sociais que as envolvem e à preocupação com os jovens de hoje.

\section{Sentimentos expressos pelas mulheres climatéricas referentes à fase da vida em que se encontram}

\subsection{Isso é normal... temos que aceitar}

O sentimento mais evidenciado nas falas das mulheres é o de normalidade, pois o climatério faz parte do ciclo normal da vida, ou seja, é um fato fisiológico; assim, toda mulher que atingir a meia-idade ira vivenciá-lo, independentemente de sua nacionalidade, cor, cultura, escolaridade, profissão, nível sócio-econômico e estado civil, visto que uma decorrência normal no ciclo de vida feminina.

( ) Eu acho que depende de cada uma a forma de se sentir, se gostar, viver bem, porque estas coisas acontecem, são normais.

( ) Eu acho que é um processo, tudo nasce, cresce, procria e morre, só que a gente tem que aprender a se preparar, tem que se amar do jeito que está.

( ) É uma evolução natural do ser humano, que, com o passar dos anos, se transforma.

Gutiérrez (1992, p. 61) refere-se ao fato da normalidade do climatério da seguinte forma:

(...) processo normal de vida das mulheres: nascimento, primeira infância, infância, adolescência e a primeira menstruação, meiaidade e menopausa, velhice e morte... é uma fase natural da vida e não uma doença. Quanto mais compreendermos este processo, melhor seremos capazes de lidar com qualquer problema que possa ocorrer (...).

E Sand (1995, p. 8) confirma: “(...) o fim do ciclo menstrual não tem preconceitos, ele acontece para todas as mulheres, é tão certo como a morte, é uma viagem que toda mulher fará (...)".

\subsection{Climatério e seus sintomas, uma fase difícil...}

Nessa fase da vida da mulher, em que há a diminuição dos níveis hormonais, ocorrem diversas alterações psíquicas, físicas ou emocionais; assim, a mulher terá de se adaptar a uma nova forma de vida, conforme as manifestações que lhe forem impostas. Segundo Almeida (1993, p. 13), 
"a mulher vê-se envolvida num complexo emaranhado de instabilidade neuro-hormonal que lhe exigira mais do que nunca capacidade adaptativa. É nessa fase que, seguramente, a mulher está mais fragilizada orgânica e emocionalmente (...)".

Nas falas que seguem pode-se perceber o porquê das dificuldades:

( ) A idade do climatério é a idade do ai-ai, da dorzinha, um dia dói a perna, no outro a coluna e outro dia dói não sei o que, tem é que se acostumar... tem que ir em frente.

( ) Eu já senti muita coisa disso aí que ela falou... (irregularidade do ciclo menstrual, fogachos, irritabilidade, diminuição da auto-estima, depressão, secura da mucosa vaginal e oral, diminuição da libido, pele seca, aumento da sensibilidade, labilidade de humor...)

( ) Vejo meu corpo envelhecendo, flácido, seios e nádegas caindo, engordando, pele ressecada... eu não estava preparada para todas essas mudanças...

Para Marinho (1995), a maioria dos sinais e sintomas típicos do climatério resulta da diminuição dos níveis de estrogênios circulantes, e essas alterações endócrinas tem um forte impacto sobre as funções psíquicas e vegetativas do organismo feminino, podendo resultar em várias manifestações, esquematizadas por Martins (1996) em quatro grupos distintos: / alterações psíquicas/ alterações nervosas e dos vasos sangüíneos/ alterações geniturinárias/ e alterações musculares, ósseas e cutâneas.

Todas as mulheres apresentam sintomatologia no climatério, mas em uma de cada quatro isso aparece de forma exacerbada. Ainda seguindo o pensamento de Marinho:

"Além dos sintomas evidentes e clássicos do climatério como os fogachos ou ondas de calor e sudorese noturna, outras alterações a curto prazo também são conseqüentes ao hipoestrogenismo como alterações do humor, insônia, irritabilidade, ansiedade e dificuldade de concentração... a médio prazo aparecem os sintomas na área urogenital, como ressecamento vaginal, dispareunia e incontinência urinária... a pele ficará mais delgada e ressecada... há também dores articulares, a longo prazo e de forma silenciosa vão ocorrer as conseqüências mais importantes do déficit estrogênico: a osteoporose e o aumento do risco cardiovascular" (p. 4).

\section{3 É mais fácil quando não se está só...}

A mulher climatérica necessita de apoio tanto familiar quanto dos profissionais de saúde para poder atravessar essa fase difícil, visando garantir uma melhor qualidade de vida, tanto física quanto emocional. 
( ) Lá em casa nós estamos envelhecendo juntos, ... então, tem que se conversar, porque não é só tu que está mudando o corpo, como eu estou envelhecendo, meu marido também tá, e ele tem que ver isso...

(...) Ele não me entendia e o que ele fez, procurou uma companheira fora. Se o homem acompanhar a mulher, se prepararem, eu me preparei, mas ele não, pra passar essa fase comigo (...).

(...) Nunca a enfermeira, médico e até o ginecologista conseguiam entender essa faixa. Quantas mulheres que eles diziam estar com fricote... então, achei importante que agora a enfermagem está se preocupando( ).

Há concordância das falas com a descrição de Halbe (1995, p. 34):

(...) outra relação problemática neste período pode ser a do casal. O companheiro pode não compreender os sintomas do climatério, podendo esta época ser um grande descompasso entre o marido e a mulher. Se o relacionamento entre os dois já não era bom, o climatério pode ser o momento de explosão da falência por potencializar as dificuldades, porém, se o casal tem cultivado a atitude de enfrentar juntos todos os problemas da vida, os decorrentes dessa transição serão superados com maior facilidade por ambos.

No que se refere aos profissionais da saúde, Marinho (1995, p. 103) sugere que "o trabalho deve ser desenvolvido em equipe multiprofissional formada por ginecologistas, psicólogos, fisioterapeutas, psiquiatras e a enfermagem, priorizando o atendimento a mulher climatérica de forma global, objetivando atenção integrada a mulher nessa etapa da sua vida".

Nesse quadro, cremos que a enfermagem deve refletir acerca da relação prática que estabelece com as mulheres na fase do climatério, pois a profissional dessa área, especialmente a que atua na saúde pública, pode se constituir em um elemento de grande valia, desenvolvendo um programa de atenção que vise a melhoria da qualidade de vida dessas mulheres de meia-idade.

\subsection{O corpo é um, a experiência de vida é outra...}

No relato das mulheres, pode-se perceber que, apesar de elas sentirem seus corpos envelhecendo, também se sentem gratificadas pelos anos que já viveram e pelas experiências que acumularam nesses. Porém, essa forma de ver tal fase depende muito da sua personalidade, do modo como orientaram sua vida e das suas realizações pessoais.

(...) eu queria a experiência que eu tenho hoje, mas com meu corpinho de vinte. 
(...) às vezes eu até gosto de ver as minhas ruguinhas, porque assim eu vejo como eu vivi, então eu me sinto bem comigo.

(...) vejo rugas, sinais do tempo em meu rosto, alguns cabelos brancos, seios um pouco caídos, mas me vejo realizada, mulher que já passou, já viveu mais da metade de sua existência.

Valorizando a experiência de vida, Képès (1994, p. 219) considera que:

a experiência passada não é somente o máximo quantitativo de um certo número de práticas que permitem repetir com mais destreza e clarividência as experiências seguintes... a experiência é a capacidade de prever, de aproveitar, de experimentar com uma acuidade cada vez mais aguçada o instante vivido em todas as suas dimensões.

Nesse sentido, Halbe (1995) afirma que a mulher irrealizada na maternidade, na vida sexual, e que valoriza excessivamente a juventude no sentido da beleza física, sofre com o climatério um verdadeiro golpe; já, a mulher que se realizou durante a vida tem sua autoconfiança aumentada à medida que envelhece.

Concordando com o pensamento de Halbe, Almeida (1993) descreve as repercussões das experiências passadas sobre os sentimentos, afirmando que:

toda experiência de perda na vido provoca revivescência de experiências passadas, de lutas, e de aspirações frustradas (...), por outro lado, toda aquisição que realizamos na vida age como uma proteção contra sentimentos de vazio ou perda. Estes processos de experiências de perdas e aquisições se desenvolvem principalmente no inconsciente. A somação e superposição de situações conflitivas explicam severas reações depressivas em algumas pessoas frente a vivências (...) (p. 28).

\subsection{Se cuide... recursos existem...}

Certas práticas podem fazer com que a mulher climatérica mantenha uma vida mais saudável, como praticar exercícios, manter uma dieta equilibrada, deixar o tabagismo, iniciar uma terapia de reposição hormonal, além da opção por cirurgia plástica, a fim de melhorar sua aparência física e com isso, elevar sua auto-imagem.

Freedman (1994, p. 260, 264) salienta que:

a medida que a ciência aperfeiçoa suas técnicas a serviço da beleza, o caminho cirúrgico torna-se cada vez mais tentador... a cirurgia plástica pode realizar algumas coisas, nem tudo. Não é mágica. Não vai transformar radicalmente sua personalidade... 
se você espera milagres, certamente vai ficar desapontada. A plástica pode melhorar sua aparência e ajudá-la a gostar mais de você... entretanto, os custos e riscos potenciais da cirurgia são relativamente altos, há outros métodos para se adquirir amor ao corpo.

Nos seguintes relatos, observa-se a forma que algumas mulheres encontraram para cuidar um pouco de si:

(...) claro que se poder se cuidar indo na academia, ou até fazer uma plástica... você tem mais é que usar os meios que pode pra ficar com tudo em cima.

(...) tomo hormônios, tomo cálcio, faço hidroginástica e caminho diariamente.

(...) tem que se cuidar na alimentação, fazer caminhadas (...)

Almeida (1993, p. 18) reforça que:

o exercício físico, o exercício mental, a dieta adequada, o não uso de álcool e fumo, a comunicação de sentimentos verbalizados e examinados abertamente, o amor, a relação sexual, serão os elementos que irão mobilizar e equilibrar no organismo as endorfinas, ou o HDL colesterol, o cálcio, e que vão proteger contra as depressões, os isolamentos, a arterosclerose e a osteoporose, fazendo com que se necessite de um mínimo de suporte medicamentoso.

\section{Preconceitos sociais em relação a mulher climatérica}

Ninguém vive fora de um contexto social e cultural, e a mulher climatérica sente dificuldades desde as mais simples, como a compra de uma roupa, até a mais complexa, como a busca de uma oportunidade de trabalho. As mulheres não preocupam de estarem envelhecendo, mas, sim, de parecerem mais velhas e serem tratadas como tais. Nossa cultura reverencia o jovem em detrimento dos mais velhos; as propagandas mostram apenas rostos jovens e perfeitos, sugerindo, que a mulher deva esconder os sinais dos anos; disfarçar as rugas, tingir os cabelos e realizar cirurgias plásticas, hoje quase obrigatórias após os quarenta. Em oposição, os homens, com seus cabelos grisalhos e início de calvicie, são considerados charmosos.

\subsection{O espaço é seletivo...}

Halbe (1995) justifica os preconceitos dizendo que a sociedade construiu estereótipos da mulher climatérica, as quais foram inculcados em todos 
nós pelos diferentes processos educativos pelos quais passamos. Entre esses está a imagem da mulher de meia-idade, que é construída socialmente de forma negativa. Nota-se isso nas falas a seguir:

( ) Entre dez confecções, nove são para meninas, pra nós hoje em dia só querem vender cirurgia plástica.

(...) os modelos são todas mocinhas, não tem modelo de meiaidade nem nas propagandas de cremes.

(...) dai quando a gente coloca uma saia mais curta, uma blusa mais justa dizem: olha lá está querendo se fazer de jovem.

(...) se não existisse a televisão mostrando só o que é belo, o que é ideal, não seria assim...

De acordo com Freedman (1994, p. 211), as idéias sobre aparência e envelhecimento são determinadas pela mídia; quem tem importância nas mensagens comerciais são as magras, bonitas, sensuais e jovens. Em decorrência disso, "quanto maior sua ansiedade por parecer mais velha, maior seu desejo de produtos que lhe façam parecer mais jovem... mas, quando você é embalada em uma imagem de adolescente é menos provável que seja levada a sério, e também lhe é negada sua própria maturidade."

\subsection{O mercado de trabalho}

Estudos demonstram que mulheres climatéricas que trabalham fora de casa, de uma forma geral, tem mais saúde física e mais amor próprio do que as que permanecem em casa. Porém, nesta faixa etária, a mulher que procura emprego é excluída no mundo do trabalho, por ser vista como se encaminhando à velhice. A sociedade associa a velhice às doenças, razão pela qual acaba eliminando a mulher climatérica da seleção de funcionários; assim, esquece-se de que ela já não terá problemas com gravidez e licençamaternidade, por que sua vida já está equilibrada e tem perfeitas possibilidades de controlar os sintomas do climatério.

Para Halbe (1995, p. 33),

(...) um grande problema na vida da mulher que sempre trabalhou fora é que no período do climatério ela está enfrentando uma aposentadoria, esse quadro soma-se aos demais dando-lhe a sensação de 'término' e algumas se abatem diante dessa hipótese deprimindo-se ainda mais; já outras que sempre optaram por ficar em casa se sentirão inúteis com a saído dos filhos do lar $e$ enfadadas com um relacionamento monótono com seus maridos, tentam partir para uma atividade profissional, porém fica difícil se ela não teve nenhuma experiência de trabalho durante grande período (...) 
O sentimento de exclusão e seletividade aparece nas seguintes falas:

(...) no mercado de trabalho a idade influencia, sentimos que, com sutileza, somos postas de lado( ).

(...) realmente, no campo de trabalho a idade influencia, eu sou secretária executiva e, na mesma função, uma menina ganha o dobro que eu ( ).

( ) A sociedade não vê a mulher mais velha como mais madura, mais preparada, mais experiente, ela vê ofísico e por ele tira suas conclusões, geralmente erradas ( ).

\subsection{As próprias pessoas se discriminam}

Apesar da mulher de a meia-idade estar sentindo na pele os preconceitos sociais e se deprimir com isso, ela também tem estigmatizado em sua mente que a climatério/menopausa é a porta aberta para a velhice. Então, nesta fase, começa a privar-se de certas atividades sociais, como se fossem permitidas somente aos jovens. A reclusão da própria pessoa, pensando não dispor mais da sedução, da beleza, do vigor de seu corpo e sua mente, leva a mulher a isolar-se para evitar situações sentidas como ameaçadoras.

Entretanto, viver com satisfação, alegria e prazer não deve ser só privilégio dos jovens e, sim, de todos que estão vivos, pois não basta dar anos à vida, é necessário dar vida aos anos. Assim, é preciso que a mulher climatérica saiba vencer os seus próprios preconceitos e medos; caso contrário, a sociedade nunca a irá ver como capaz de desfrutar os mesmos ambientes que as mais novos.

(...) nessa idade tu procura a tua turma. Tu não vai ir no Bier Site, tu mesmo se discrimina, não vai se achando velha.

(...) ocorre também no campo de estudo, tu pensa: "Poxa, vai ser só eu de velha", e analisei e procurei a curso de assistência social, que tem pessoas com mais de 35 anos.

Conforme Almeida (1993, p. 19),

é difícil para a mulher enxergar e analisar sua aparência dentro da sua real faixa etária, pois, o ponto de referência para a avaliação é quase sempre o da juventude perdida, acarretando então tristeza e depressão. Posicionar-se dentro da real faixa etária, sem esconder ou mentir a idade, reforça as vantagens que a vida atual conferiu a mulher e colabora para decodificar a imagem de que a climatérica é uma velha, acabada para a vida sexual e para a sociedade, sociedade esta que festeja o nascimento, a menarca, os 15 anos, a formatura, o casamento e até se reúne para chorar seus mortos, mas quanto ao climatério nada faz pois o enfoque negativo e o recurso da negação da idade dominam seus hábitos culturais (...) 
Cabe à própria mulher climatérica lutar pelo seu espaço, modificando os valores de uma sociedade na qual a pessoa idosa é desrespeitada e desdenhosamente chamada de "velha", não no sentido carinhoso, amigo, mas no sentido de decrepitude, de "gagá".

\section{Preocupação com a futuro da juventude atual}

\subsection{Juventude de hoje, velha de amanhã... o que vai acontecer?}

Faz parte da mulher a preocupação com a bem-estar dos outros, como se isso fosse um instinto maternal. Durante o encontro grupal, revelou-se uma certa inquietude com relação à juventude atual, para a qual, hoje, o que é importante é a aparência física, a beleza e os modismos, como evidencia seguinte fala:

(...) Eu acho que nós, nessa fase, nos aceitamos mais do que a geração que está por vir, pra elas vai ser pior porque pra elas o que vale é o corpo, a aparência. Nós, com 14 anos, brincávamos de boneca, enquanto hoje elas já estão na academia enlouquecidas. Então essa fase dos quarenta e poucos pra elas vai ser mais difícil de aceitar, vão se escabelar quando começar a cair tudo ( ).

Para Freedman (1994, p. 204)

a obsessão pela aparência e pelo envelhecimento estão associados a um culto da juventude que causa problemas... e para aquelas que desfrutam a juventude e jamais pensam em envelhecer não precisar aprender que o corpo vai se modificando e podemos amá-lo mesmo que esteja enrugado... quem não consegue se imaginar ficando grisalha, ou se ao pensar na meia-idade chega a sentir aversão ao corpo, está fugindo do realidade (...)

\section{CONSIDERAÇÕES FINAIS}

Retornando ao nosso objetivo, que é conhecer os sentimentos da mulher climatérica sobre a imagem corporal, suas dificuldades e os preconceitos existentes na sociedade, foi possível perceber que, ao mesmo tempo em que ela nos diz que considera normal tudo o que lhe acontece nesse período da meia-idade, é-lhes também difícil, pois exige mudanças em seu estilo de vida.

Essa fase é realmente "um ponto crítica da vida" porque, quando se fala em meia-idade, climatério, não se está referindo apenas mais um ano de vida, visto que, juntamente com a idade, vêm as suas conseqüências - as 
alterações -, que poderão ser inúmeras. E dessas alterações, por vezes visíveis, derivam os preconceitos sociais, que julgam as pessoas pelo seu exterior, razão pela qual, a mulher climatérica é percebida de forma negativa, sobretudo num tempo em que a juventude é idealizada.

No que se refere à saúde da mulher, veremos que o foco está direcionado somente a sua vida reprodutiva, dando ênfase à assistência pré-natal, puerpério, planejamento familiar, prevenção de câncer de mama e colo uterino. Quanto ao climatério, pode não fazer parte da vida das mulheres.

Acredito, por isso, ser de extrema importância que o planejamento da assistência à saúde da mulher também seja voltado à mulher climatérica, para que ela tenha a possibilidade de receber educação, informações e suporte emocional, o que lhe possibilitará viver melhor esta experiência. Para isso, no entanto, é necessária uma nova visão por parte dos profissionais da área da saúde, considerando a mulher como um todo, na sua forma social, econômica, cultural, educacional e emocional.

\section{REFERÊNCIAS BIBLIOGRÁFICAS}

ALMEIDA, A. B. de. Climatério. Porte Alegre: Artes Médicas, 1993.

FREEDMAN, R. Meu corpo... Meu espelho. Rio de Janeiro: Rosa dos Tempos, 1994.

GUTIERREZ, E. Mulher na menopausa: declínio ou renovação. Rio de Janeiro: Rosa dos Tempos, 1992.

HAAS, R. E. Desenvolvimento da imagem corporal no adulto. Passo Fundo, 1995. HALBE, H.; PINOTTI, J. A.; HEGG, R. Menopausa. São Paulo: Roca, 1995.

KEPES, S.; THIRIET, M. Mulheres de 50 anos. Porto Alegre: L\&PM, 1994.

MARINHO, R. M. Climatério. Rio de Janeiro: Médica e Científica, 1995.

MARTINS, A. A. Menopausa sem mistérios: as mais recentes descobertas. Rio de Janeiro: Rosa dos Tempos, 1996.

MORETTI, E. Imagem corporal: do conceito aos cuidados. Passo Fundo: UPF, 1992.

PENNA, L. Corpo sofrido e mal amado. São Paulo: Summus, 1989.

SAND, G. Está quente aqui ou sou eu? Um exame pessoal dos fatos, equívocos e sensações da menopausa. São Paulo: Summus, 1995.

VISCOTT, D. S. A linguagem dos sentimentos. São Paulo: Summus, 1982. 